\title{
Anomalous secular sea-level acceleration in the Baltic Sea caused by isostatic adjustment
}

\author{
Giorgio Spada ${ }^{1,}$, Marco Olivieri $^{2}$, Gaia Galassi $^{1}$ \\ ${ }^{1}$ Università di Urbino, Dipartimento di Scienze di Base e Fondamenti (DiSBeF), Urbino, Italy \\ ${ }^{2}$ Istituto Nazionale di Geofisica e Vulcanologia, Sezione di Bologna, Italy
}

\author{
Article history \\ Received April 17, 2014; accepted June 11, 2014. \\ Subject classification: \\ Sea-level change, Glacial isostatic adjustment, Rheology.
}

\begin{abstract}
Observations from the global array of tide gauges show that global sealevel has been rising at an average rate of $1.5-2 \mathrm{~mm} / \mathrm{yr}$ during the last $\sim 150$ years [Douglas 1991, Spada and Galassi 2012]. Although a global sea-level acceleration was initially ruled out [Douglas 1992], subsequent studies [Douglas 1997, Church and White 2006, Jevrejeva et al. 2008, Church and White 2011] have coherently proposed values of $\sim 1$ $\mathrm{mm} /$ year/century [Olivieri and Spada 2013]. More complex non-linear trends and abrupt sea-level variations have now also been recognized. Globally, these could manifest a regime shift between the late Holocene and the current rhythms of sea-level rise [Gehrels and Woodworth 2013], while locally they result from ocean circulation anomalies, steric effects and wind stress [Bromirski et al. 2011, Merrifield 2011]. Although isostatic readjustment affects the local rates of secular sea-level change [Milne and Mitrovica 1998, Peltier 2004], a possible impact on regional acceleration has been so far discounted [Douglas 1992, Jevrejeva et al. 2008, Woodworth et al. 2009] since the process evolves on a millennium time scale [Turcotte and Schubert 2002]. Here we report a previously unnoticed anomaly in the long-term sea-level acceleration of the Baltic Sea tide gauge records, and we explain it by the classical post-glacial rebound theory and numerical modeling of glacial isostasy. Contrary to previous assumptions, our findings demonstrate that isostatic compensation plays a role in the regional secular sea-level acceleration.
\end{abstract}

While studying the regional patterns of the global sea-level acceleration (GSLA) [Olivieri and Spada 2013], we noted that accelerations in secular tide gauge time series from the Baltic Sea tend to exceed, albeit slightly, those from records of comparable length and quality from elsewhere. Tide gauges from this region are generally not exploited in GSLA studies [Church and White 2006, Woodworth et al. 2009] because these are believed to be too strongly influenced by local circulation [Jevrejeva et al. 2008] and possibly by GIA. To confirm the existence of an anomalous acceleration, we have now compared the sea-level trends obtained from
60 validated Baltic Sea records (Figure 1a, BS) with those shown by the global set of tide gauge time-series previously employed by Douglas [1991, 1997] and obeying rigorous quality constraints in terms of record length and completeness. Contrary to the former, the latter are not from regions that were deeply covered by ice at the Last Glacial Maximum ( 21,000 years ago) where isostatic disequilibrium is still causing crustal uplift, and consequently a relative sea-level fall of several millimeters per year [Steffen and Wu 2011]. We have augmented the global set with ten records of comparable length, recently shown [Spada and Galassi 2012] to minimize the contamination from Glacial Isostatic Adjustment (GIA) and the sensitivity to the model adopted to perform the GIA correction. The resulting global set consists of 32 records (Figure 1b, GL); it includes sites largely insensitive to GIA and thus more suitable to constrain the long term sea-level changes driven by current climate variations.

Following Douglas [1992], sea-level accelerations in Figure 1 have been computed as twice the quadratic term of a second-degree best-fitting polynomial. The distribution of the accelerations obtained for sets BS and GL are shown by the histograms of Figure $2 a$ (here, we have found convenient to express accelerations in units of $\mathrm{mmyc}=\mathrm{mm} / \mathrm{yr} /$ century). By a Student t-test with Welch correction [Welch 1947] we have verified that the weighed averages of the two distributions, shown Figure 2b, are significantly different at the 95\% confidence level. This supports the hypothesis that the sea-level accelerations for the BS tide gauges are, on the average, larger than those belonging to the GL set. According to our computations, the anomaly (i.e. the difference in the average sea-level accelerations for the two sets), can be quantified as $N_{a}=(0.2 \pm 0.2)$ mmyc. The anomaly is small, but it is not negligible compared to 

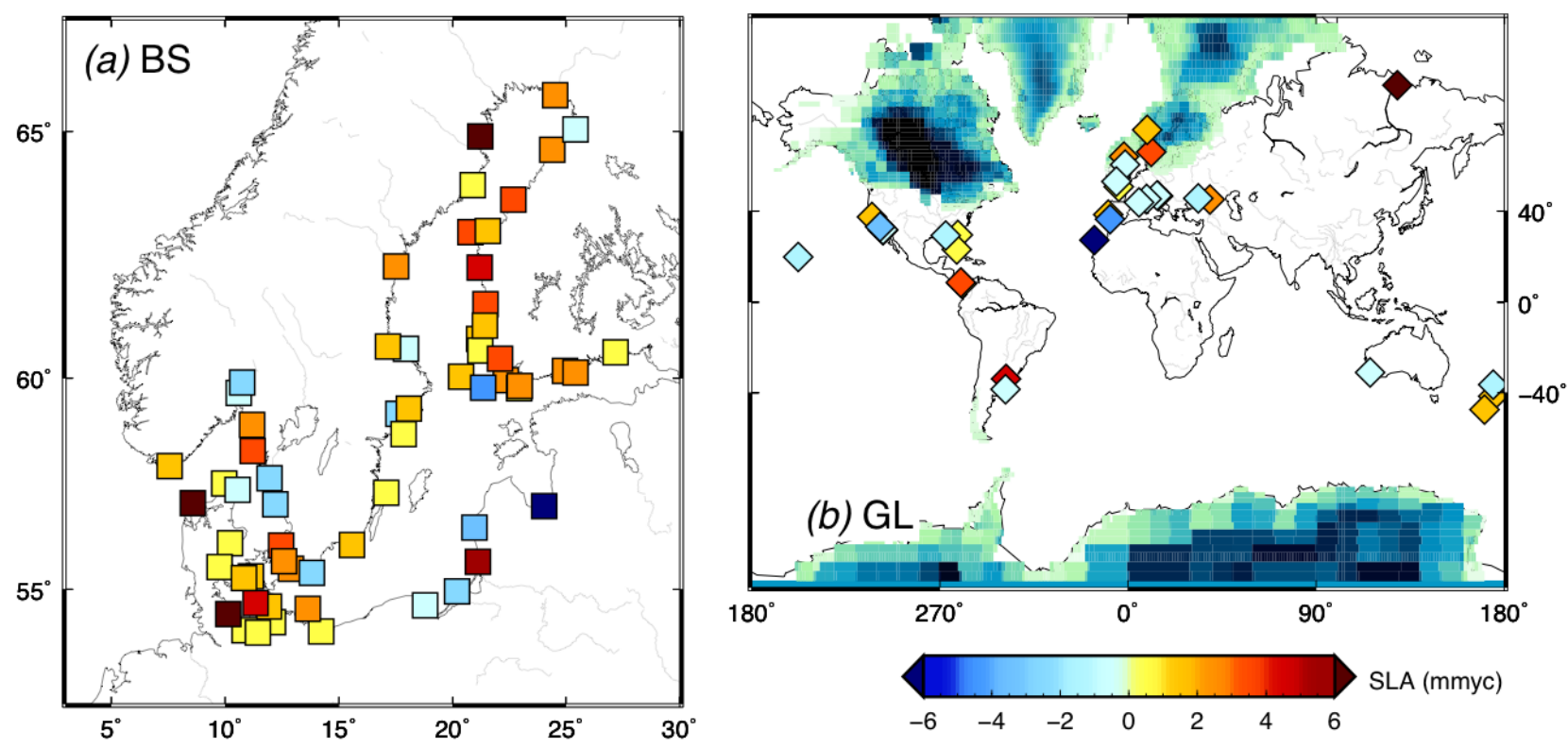

Figure 1. Location of tide gauge instruments. (a) Location of Baltic Sea (BS) tide gauges (number of records: 60, minimum record length: 100 years, average completeness: $92 \%$ ). In (b) the global (GL) set is considered (32, 56 years, 58\%). Shades of blue in (b) depict the thickness of the ice sheets at the Last Glacial Maximum according to the GIA model ICE-5G(VM2) [Peltier 2004]. Colors of squares and diamonds denote the local sea-level acceleration ( 1 mmyc $=1$ millimeter per year per century). All time series and tide gauge station information are extracted from the PSMSL database of annual RLR (revised local reference) records [Woodworth and Player 2003].

GSLA estimates so far obtained in the literature, which are close to 1 mmyc [Olivieri and Spada 2013].

The positive sign for $N_{a}$ can be explained, in a straightforward way, invoking the physics of postglacial rebound [Turcotte and Schubert 2002]. In formerly glaciated regions like the Baltic Sea, relative sea-level has been gradually falling since the end of deglaciation $\sim 8,000$ years ago, as a direct consequence of the post-glacial uplift of the Earth's crust [Steffen and Wu 2011]. According to the classical post-glacial rebound theory for a Newtonian viscous Earth [Turcotte and Schubert 2002], after unloading, the free surface relaxes toward isostatic equilibrium following an exponential law. Hence the rate of relative sea-level fall was larger immediately after the end of ice melting and it is now progressively increasing toward less and less neg- ative values. At the BS tide gauges in Figure 1a, this today implies an excess positive sea-level acceleration compared to distant sites, which are less (or not at all) influenced by the post-glacial rebound process; this explains why the observed anomaly $N_{a}$ is positive.

By more quantitative arguments, it is possible to predict the order of magnitude of the anomalous acceleration. For a simplified half-space model, the postglacial displacement $u(t)$ of the Earth's free surface decays with time exponentially [Turcotte and Schubert 2002]. Hence, the rate of vertical uplift $v(t)$ scales with $v(t)=-\mathfrak{u}(t) / \tau_{r}$, where $t$ is time and $\tau_{r}$ is the Maxwell relaxation time of the Earth's mantle [Turcotte and Schubert 2002]. Since vertical uplift dominates the relative sea-level variation $s(t)$ in formerly glaciated regions [Steffen and Wu 2011], neglecting gravitational effects
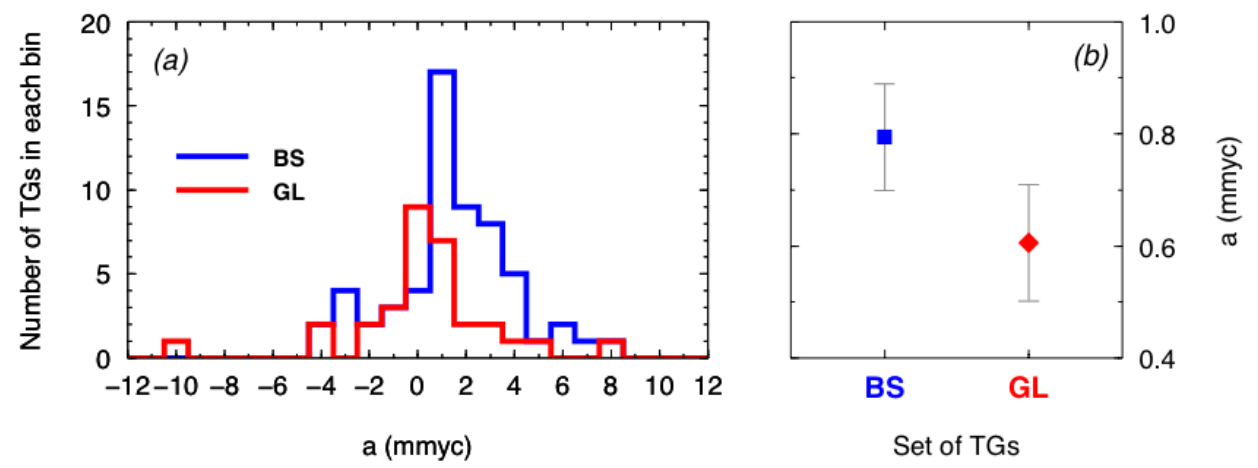

Figure 2. Distribution of observed sea-level accelerations. (a) Sea-level accelerations observed for the Baltic Sea (BS, blue) and the global (GS, red) sets of tide gauges. (b) Average sea-level accelerations for the two sets and their standard deviations. For BS and GL, the accelerations have average values of $(0.8 \pm 0.1)$ and $(0.6 \pm 0.1)$ mmyc, respectively. Their difference defines the anomalous sea-level acceleration $N_{a}=$ $(0.2 \pm 0.2)$ mmyc. 
[Peltier 2004] we can write $s(t)=-u(t)$, which taking the second derivative gives $a(t)=v(t) / \tau_{r}$, where $a(t)$ is the local sea-level acceleration. We note that the rate of present day sea-level change and its acceleration are negatively correlated, namely $r(t)=-a(t) \tau_{r}$. The relaxation time $\tau_{r}$ is obtained analytically in terms of the bulk properties of the Earth and the spatial wavelength of the ice load [Turcotte and Schubert 2002]. Assuming a characteristic uplift rate $v \sim 10 \mathrm{~mm} / \mathrm{yr}$, representative of the Baltic region [Steffen and $\mathrm{Wu} 2011$ ], for $\tau_{r}=4,400$ years [Turcotte and Schubert 2002] (suitable for the size of Fennoscandia) and a bulk mantle viscosity [Haskell 1936] of $10^{21} \mathrm{~Pa} \cdot \mathrm{s}$, we obtain $a \sim 0.2 \mathrm{mmyc}$ at present time, consistent with the amplitude of the observed anomaly $N_{a}$ in Figure $2 \mathrm{~b}$. Since $a(t)$ scales with $v(t)$, the anomalous acceleration is doomed to disappear as soon as the surface of the Earth will reach, in a few millennia, a full isostatic compensation $(v(t)=0)$.

To substantiate the order-of-magnitude estimates above, we have employed a realistic GIA model to compute and visualize the "fingerprints" [Milne and Mitrovica 1998, Mitrovica et al. 2001] describing patterns of present-day sea-level rates and acceleration associated with GIA. Here we have implemented model ICE$5 \mathrm{G}(\mathrm{VM} 2)$ [Peltier 2004] for the melting history of the late-Pleistocene ice sheets in the open source code SELEN [Spada and Stocchi 2007, Spada et al. 2012]. Our computations account for the horizontal migration of shorelines and for the impact of Earth rotation variations on sea-level change, and assume a three-layer vis- coelastic mantle with Maxwell rheology with viscosities obtained by volume-averaging profile VM2 [Peltier 2004]. The two fingerprints are shown in Figures $3 a$ and $3 \mathrm{~b}$, respectively; the second is obtained from the first by numerical time differentiation. We have verified that their global shape would not change perturbing the viscosity profile of the mantle within reasonable bounds, nor adopting alternative GIA models, characterized by different assumptions about the Earth's viscosity profile and including a distinct time chronology for the melting of the late-Pleistocene ice sheets [Lambeck and Johnston 1989, Lambeck et al. 1989].

The GIA fingerprint for the rate of sea-level change in Figure 3a clearly reflects the direct effect of unloading, which dominates across the previously glaciated regions causing an enhanced sea-level fall. Finer details of the map have been quantitatively explained in terms of "continental levering" (tilting of coastal regions due to ocean water loading) and "ocean syphoning" (migration of water from the far field of former ice sheets to fill the space left by the collapsing isostatic forebulges) [Mitrovica and Milne 2002]. This pattern is indeed well known since it is commonly employed to decontaminate the rates of sea-level variations observed at tide gauges from the effects of GIA [Douglas 1991, Spada and Galassi 2012]. However, the fingerprint of sea-level acceleration in Figure $3 \mathrm{~b}$ is shown here for the first time, since previous studies have assumed that GIA has negligible effects on the GSLA [Douglas 1992, 1997, Church and White 2006, Jevrejeva et al. 2008, Woodworth et al.
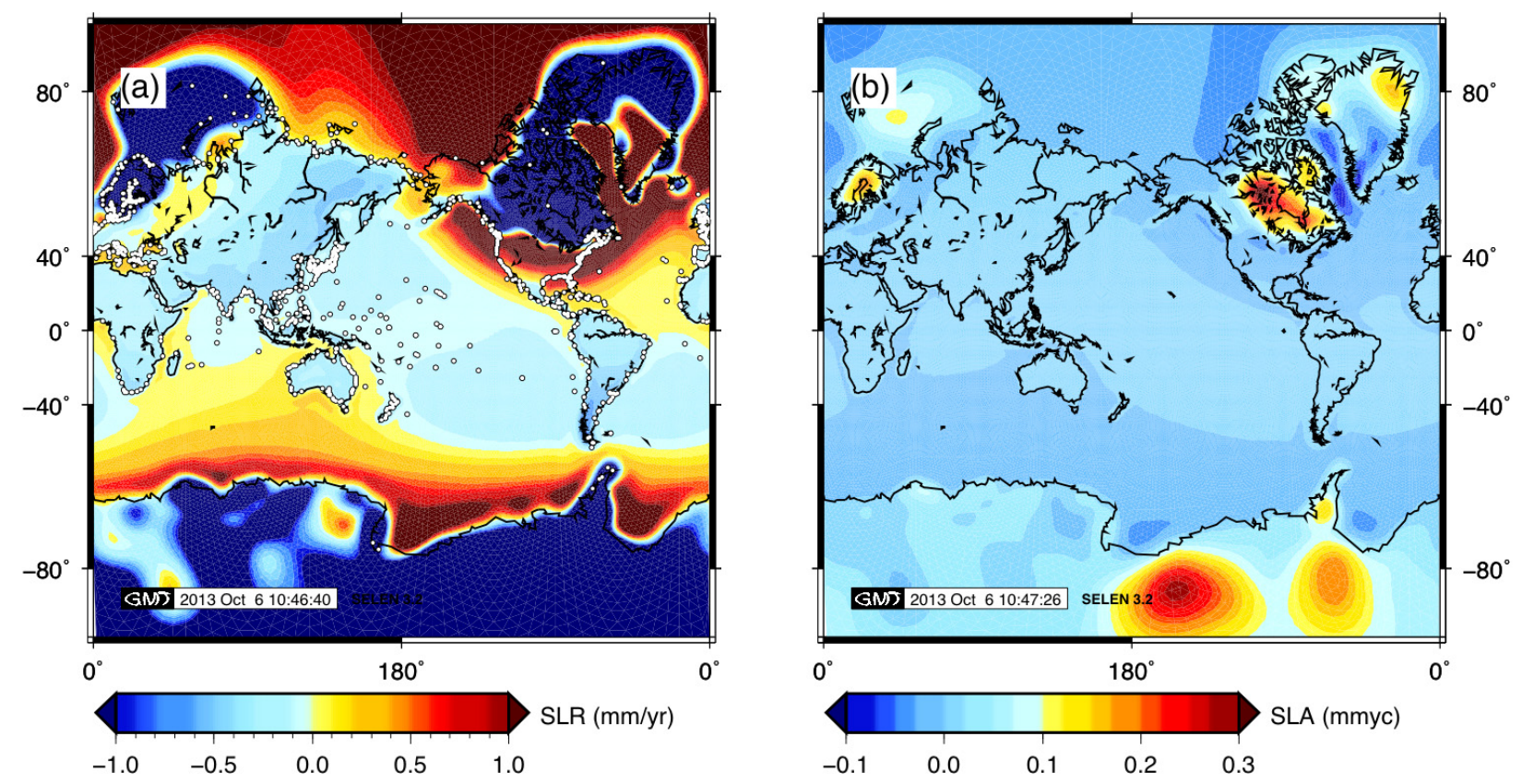

Figure 3. GIA sea-level fingerprints. GIA fingerprints for the rate of sea-level rise (a) and its time-derivative (sea-level acceleration) (b), computed at present time for model ICE-5G(VM2) [Peltier 2004] and obtained by code SELEN [Spada and Stocchi 2007, Spada et al. 2012]. In (a) the dots show the PSMSL tide gauges, and the actual rates in polar regions far exceed the range of the color table. Since relative sea-level is defined by the offset between the geoid height and the Earth's solid surface [Milne and Mitrovica 1998], these fingerprints are also defined across the continents. 
2009, Olivieri and Spada 2013] and its importance has been overlooked.

Similarly to the correction for the rate of sea-level rise (Figure 3a), that for the acceleration (3b) has a vanishing average across the oceans, and the mean value at the locations of the global set of PSMSL tide gauges (see Figure 3a) is effectively negligible $\left(<10^{-2}\right.$ mmyc), which justifies the assumptions in previous GSLA studies. However, the regional impact of GIA-induced sealevel acceleration is apparent, especially in areas which are still subject to significant isostatic disequilibrium like the Baltic Sea, the Hudsons Bay region, northern Greenland and West Antarctica. Across the Baltic Sea, the GIA acceleration amounts to $\sim 0.1-0.2$ mmyc, in agreement with the order of magnitude observed in this study and with the classical post-glacial rebound theory. The anomaly attains its largest amplitude $(>0.3$ mmyc) in West Antarctica and in central Canada. Since century-long tide gauge observations from the Hudsons Bay region are not available, it is impossible to compare predictions for this region with instrumental data. The negative correlation between the two fingerprints in Figures 3a and $3 \mathrm{~b}$ is apparent and consistent with the extremely simplified post-glacial rebound theory discussed above. However, their ratio, which can be interpreted as the GIA "relaxation time", is not constant since the complex rheological layering of the GIA model employed here implies a multi-exponential relaxation [Peltier 2004, Spada and Stocchi 2007]. Using directly the results from Figure 3, for the Baltic Sea region we obtain $\tau_{r} \sim 5,000$ years, in agreement with the classical Haskell theory [Haskell 1936].

In response to GIA, tide gauge records located along the coasts of the Baltic Sea exhibit a small - but significant - long-term sea-level acceleration in excess to those in the far field of previously glaciated regions. The sign and the amplitude of the anomaly is consistent with the post-glacial rebound theory and with realistic numerical predictions of GIA models routinely employed to decontaminate the tide gauges observations from the GIA effects [Peltier 2004]. Model computations predict the existence of anomalies of similar amplitude in other regions of the globe where GIA is still particularly vigorous at present, but no long-term instrumental observations are available to support their existence. We confirm that a GIA correction for secular sea-level acceleration is not required in GSLA assessments because its average value is vanishingly small at the locations of the PSMSL tide gauges [Douglas 1992]. Nevertheless, here we have shown that GIA is contributing significantly on a regional scale, and therefore it should be recognized as one of the processes responsible for local, long-term sea-level acceleration.
Acknowledgements. Party supported by a research grant of Dipartimento di Scienze di Base e Fondamenti (DiSBeF) of the University of Urbino. All figures have been drawn using the GMT package [Wessel and Smith 1998]. Florence Colleoni is acknowledged for advice. The tide gauge data are obtained from the Permanent Service for Mean Sea Level (PSMSL) database (http: / / www.psmsl.org/).

\section{References}

Bromirski, P.D., A.J. Miller, R.E. Flick and G. Auad (2011). Dynamical suppression of sea level rise along the Pacific coast of North America: Indications for imminent acceleration, J. Geophys. Res., 116, C07005.

Church, J.A., and N.J. White (2006). A 20th century acceleration in global sea-level, Geophys. Res. Lett., 33, L01602.

Church, J.A., and N.J. White (2011). Sea-level rise from the late 19 th to the early 21 st century, Surv. Geophys., 32 (4), 585-602.

Douglas, B. (1991). Global sea sevel rise, J. Geophys. Res., 96, 6981-6992.

Douglas, B. (1992). Global sea level acceleration, J. Geophys. Res., 97 (C8), 12699-12706.

Douglas, B. (1997). Global sea-level rise: a redetermination, Surv. Geophys., 18, 279-292.

Gehrels, W.R., and P.L. Woodworth (2013). When did modern rates of sea-level rise start?, Global Planet. Change, 100, 263-277.

Haskell, N.A. (1936). The motion of a viscous fluid under a surface load, Part II, Physics, 7, 56-61.

Jevrejeva, S., J.C. Moore, A. Grinsted and P.L. Woodworth (2008). Recent global sea level acceleration started over 200 years ago?, Geophys. Res. Lett., 35, L08715.

Lambeck, K., and P. Johnston (1989). The viscosity of the mantle: Evidence from analyses of glacial rebound phenonena, In: I. Jackson (ed.), The Earth's Mantle: Composition, Structure, and Evolution, Cambridge Univ. Press, New York, 461-502.

Lambeck, K., C. Smither and P. Johnston (1989). Sealevel change, glacial rebound and mantle viscosity for northern Europe, Geophys. J. Int., 134, 102-144.

Merrifield, M.A. (2011). A shift in western tropical Pacific sea level trends during the 1990s, J. Clim., 24 (15), 4126-4138.

Milne, G., and J. Mitrovica (1998). Postglacial sea-level change on a rotating Earth, Geophys. J. Int., 133, 1-10.

Mitrovica, J., M.E. Tamisiea, J.L. Davis and G. Milne (2001). Recent mass balance of polar ice sheets inferred from patterns of global sea-level change, $\mathrm{Na}-$ ture, 409, 1026-1029.

Mitrovica, J.X., and G. Milne (2002). On the origin of late Holocene sea-level highstands within equatorial ocean basins, Quat. Sci. Rev., 21, 2179-2190.

Olivieri, M., and G. Spada (2013). Intermittent sea-level 
acceleration, Global Planet. Change. 109, 64-72.

Peltier, W. (2004). Global glacial isostasy and the surface of the Ice-Age Earth: the ICE-5G(VM2) model and GRACE, Annu. Rev. Earth Pl. Sc., 32, 111-149.

Spada, G., and P. Stocchi (2007). SELEN: a Fortran 90 program for solving the "Sea Level Equation", Comput. and Geosci., 33, 538-562.

Spada, G., and G. Galassi (2012). New estimates of secular sea-level rise from tide gauge data and GIA modeling, Geophys. J. Int., 191 (3), 1067-1094.

Spada, G., D. Melini, G. Galassi and F. Colleoni (2012). Modeling sea level changes and geodetic variations by glacial isostasy: the improved SELEN code; http:/ / arxiv.org/abs/1212.5061.

Steffen, H., and P. Wu (2011). Glacial isostatic adjustment in Fennoscandia - A review of data and modeling, Journal of Geodynamics, 52, 169-204.

Turcotte, D.L., and G. Schubert (2002). Geodynamics, Cambridge University Press, Cambridge.

Welch, B.L. (1947). The generalization of "Student's" problem when several different population variances are involved, Biometrika, 34, 28-35.

Wessel, P., and W.H.F. Smith (1998). New, improved version of generic mapping tools released, EOS, $79,579$.

Woodworth, P.L., and R. Player (2003). The Permanent Service for Mean Sea Level: an update to the 21st century, J. Coastal Res., 19, 287-295.

Woodworth, P., et al. (2009). Evidence for the accelerations of sea level on multi-decade and century timescales, Int. J. Climatol., 29, 777-789.

*Corresponding author: Giorgio Spada,

Università di Urbino, Dipartimento di Scienze di Base e Fondamenti (DiSBeF), Urbino, Italy; email: giorgio.spada@gmail.com. 